\title{
Investigation of binding properties of dicationic styrylimidazo[1,2-a]pyridinium dyes to human serum albumin by spectroscopic techniques
}

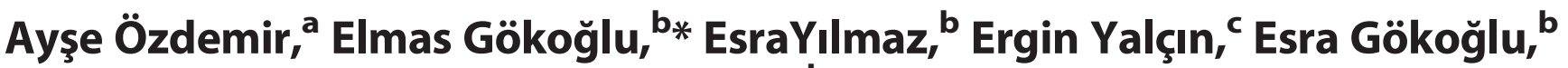 \\ Zeynel Seferoğlu ${ }^{c}$ and Turgay Tekinay ${ }^{d, e}$
}

\begin{abstract}
The binding interaction between two dicationic styrylimidazo[1,2-a]pyridinium dyes and human serum albumin (HSA) was investigated at physiological conditions using fluorescence, UV-vis absorption, and circular dichroism (CD) spectroscopies. Analysis of the fluorescence titration data at different temperatures suggested that the fluorescence quenching mechanism of HSA by these dyes was static. The calculated thermodynamic parameters $\left(\Delta \mathbf{G}^{\circ}, \Delta \mathbf{H}^{\circ}\right.$ and $\left.\Delta \mathbf{S}^{\circ}\right)$ indicated that hydrogen bonding and van der Waals forces played a major role in the formation of the dye-HSA complex. Binding distances (r) between dyes and HSA were calculated according to Förster's non-radiative energy transfer theory. Studies of conformational changes of HSA using CD measurements indicate that the $\alpha$-helical content of the protein decreased upon binding of the dyes. Copyright $\odot 2016$ John Wiley \& Sons, Ltd.
\end{abstract}

Keywords: human serum albumin; fluorescence quenching; circular dichroism; dicationic styryl dyes; binding mode

\section{Introduction}

Serum albumins are one of the most studied plasma proteins and play a vital role in the distribution and transport of drugs, nanoparticles, fatty acids, metal ions and miscellaneous small molecules in the circulatory system (1-3). The fluorescence characteristics of serum albumins provide critical information for the study of their interactions with several molecules of clinical interest $(4,5)$. Human serum albumin (HSA) is the main carrier molecule in blood plasma and can bind to many endogenous and exogenous substances. HSA is a globular protein consisting of a single polypeptide chain with 585 amino acids, and contains three structurally homologous domains (I, II and III). Each HSA domain is composed two subdomains ( $A$ and $B$ ) that are stabilized by 17 disulfide bridges and exhibit a $67 \% \alpha$-helix content. Two subdomains, site I (in subdomain IIA) and site II (in subdomain IIIA) play important roles in the binding of HSA to small molecules. Many biochemical studies have reported on the interactions of small molecules with HSA using fluorescence quenching such as derivatives of coumarin (6), acridine (7), phenanthridine (8) and imidazole $(9,10)$; sinomenine (11) phthalate plasticizers (12), helicid (13), and a benzimidazole derivative (14) etc.

Neutral and cationic styryl dyes exhibit fluorescence with high quantum yields upon interacting with biomolecules such as DNA and RNA (15-17). In addition, these dyes display excellent opto-electronic properties and are commonly studied for their potential utility in laser systems, optical or electro-optical devices and sensors (18-21). Imidazo[1,2-a]pyridines are a well studied class of molecules that are characterized by an attractive core inside an imidazopyridine ring system. They are of significant importance in the pharmaceutical industry, due to their interesting biological activities, which fall under a broad range of therapeutic classes. These molecules exhibit anti-viral, anti-inflammatory, anti-tumor, analgesic, anti-pyretic, anti-ulcer and anti-bacterial properties, and drugs containing imidazo[1,2-a]pyridine ring such as zolpidem (hypnotic) are currently available on the market (22-24). Therefore, we sought to develop novel dye structures for use in biological systems by integrating imidazopyridine units into styryl-type dicationic structures. We prepared two dicationic styrylimidazo[1,2-a]pyridinium dyes, called $\mathbf{2 a}$ and $\mathbf{2} \mathbf{b}$ for this purpose (Scheme 1) $(25,26)$. We assumed with compound $\mathbf{2} \mathbf{b}$ that the electronic effect on substituted phenyl ring with a metoxy group as an electron donor at the para position of phenyl ring might influence the binding properties of the compound to HSA, where there is an established donor-acceptor system by

\footnotetext{
* Correspondence to: Elmas Gökoğlu, Hacettepe University, Department of Chemistry, Ankara 06800, Turkey. E-mail: gokoglu@hacettepe.edu.tr

a UNAM - National Nanotechnology Research Center, Bilkent University, Bilkent 06800 Ankara, Turkey

b Department of Chemistry, Hacettepe University, Beytepe 06800 Ankara, Turkey

c Department of Chemistry, Gazi University, Ankara 06500, Turkey

d Department of Medical Biology and Genetics, Faculty of Medicine, Gazi University, 06500, Besevler, Ankara, Turkey

e Life Sciences Application and Research Center, Gazi University, 06830, Gölbaşi, Ankara, Turkey
}

Abbreviations: $C D$, circular dichroism; FRET, fluorescence resonance energy transfer; HSA, human serum albumin; IR, infra-red; NMR, nuclear magnetic resonance; RSD, relative standard deviation 

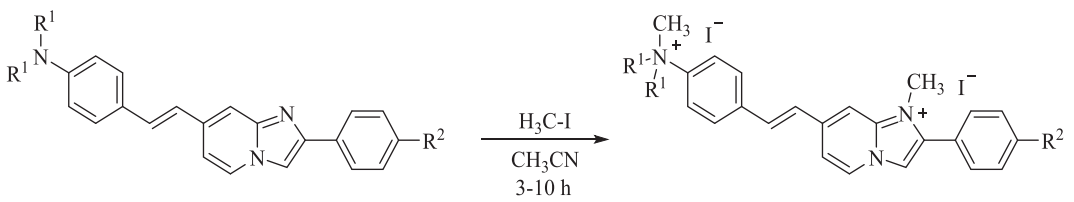

1a: $\mathrm{R}^{1}=\mathrm{Et} ; \mathrm{R}^{2}=\mathrm{H}$

1b: $\mathrm{R}^{1}=\mathrm{Et} ; \mathrm{R}^{2}=\mathrm{OMe}$

$$
\begin{aligned}
& \text { 2a: } R^{1}=E t ; R^{2}=H(87 \%) \\
& \text { 2b: } R^{1}=E t ; R^{2}=\operatorname{OMe}(94 \%)
\end{aligned}
$$

Scheme 1. Synthesis of dicationic alkylamino styrylimidazo[1,2-a]pyridinium iodide dyes $\mathbf{2} \mathbf{a}$ and $\mathbf{2} \mathbf{b}$.

resonance compared with the unsubstituted phenyl ring in compound $\mathbf{2 a}$. The compound in which the phenyl ring is substituted at the para position with the electron withdrawing group such a nitro, cyano etc. was eliminated for the interaction studies due to its limited solubility in aqueous media under same conditions. The association of the compounds $\mathbf{2} \mathbf{a}$ and $\mathbf{2} \mathbf{b}$ with HSA exhibited similar effects and moderate binding constants by fluorimetric titration compared with the interactions studies in which the metal used complexes of benzimidazole derivatives with HSA $(27,28)$. In the present study, the binding properties of $\mathbf{2} \mathbf{a}$ and $\mathbf{2} \mathbf{b}$ to HSA were investigated using spectroscopic methods.

\section{Experimental}

\section{General procedure for the synthesis and characterization of dicationic styrylimidazo[1,2-a]pyridines, $2 a$ and $\mathbf{2 b}$}

A mixture of $1 \mathrm{mmol}$ of corresponding neutral styrylimidazo[1,2-a] pyridine and $2.5 \mathrm{mmol}$ of methyl iodide was stirred in $10 \mathrm{~mL}$ of acetonitrile under reflux for 3-10 h under a nitrogen gas atmosphere. Diethyl ether was added and the mixture was filtered off. The precipitate was washed thoroughly several times with acetone and ethyl acetate and used without additional purification.

The $\mathbf{2} \mathbf{a}$ and $\mathbf{2} \mathbf{b}$ dyes were characterized by their melting points, elemental analysis, masses, nuclear magnetic resonance (NMR) and infra-red (IR) spectroscopy. Elemental analysis was performed on an Elementar Analysensysteme $\mathrm{GmbH}$ system (varioMICRO CHNS). IR spectra were recorded on a Mattson 1000 FTIR spectrometer with $\mathrm{KBr} .{ }^{13} \mathrm{C}$ and ${ }^{1} \mathrm{H}$ NMR spectra were obtained on a Bruker $400 \mathrm{MHz}$ Ultra Shielded NMR spectrometer. Mass spectra were recorded on an Agilent 1100 MSD instrument.

(E)-7-(4-(Diethyl(methyl)ammonio)styryl)-1-methyl-2-phenylimidazo [1,2-a]pyridin-1-ium iodide (2a). Light yellow powder; 0.57 g; yield 87\%; mp: 232-233 ${ }^{\circ} \mathrm{C} ;{ }^{1} \mathrm{H}$ NMR $\left(d_{6}\right.$-DMSO, $\left.400 \mathrm{MHz}\right) \delta 1.04(\mathrm{t}, 6 \mathrm{H})$, $3.52(\mathrm{~s}, 3 \mathrm{H}), 3.87\left(\mathrm{~s}, 3 \mathrm{H}\right.$ for $-\mathrm{CH}_{3}$ attached imidazo- $\mathrm{N}^{+}$and $\mathrm{m}, 2 \mathrm{H}$, ethyl $\mathrm{CH}_{2}$ adjacent to the cationic nitrogen), $3.98(\mathrm{~s}, 3 \mathrm{H}), 4.07$ (m, $2 \mathrm{H}$, ethyl $\mathrm{CH}_{2}$ adjacent to the cationic nitrogen), $7.67(\mathrm{~m}, 4 \mathrm{H})$, $7.73(\mathrm{~m}, 2 \mathrm{H}), 7.90-7.98(\mathrm{~m}, 6 \mathrm{H}), 8.44(\mathrm{br} \mathrm{s}, 1 \mathrm{H}), 8.57(\mathrm{~s}, 1 \mathrm{H}), 8.94$ $(\mathrm{d}, 1 \mathrm{H}) ;{ }^{13} \mathrm{C}$ NMR $\left(d_{6}\right.$-DMSO, $\left.100 \mathrm{MHz}\right): \delta 8.67\left(2 \times \mathrm{CH}_{3}\right), 32.7$ $\left(\mathrm{CH}_{3}\right), 63.7\left(2 \times \mathrm{CH}_{2}\right), 108.4,113.3,115.6,123.3,125.7,127.9$, 129.5, 129.7, 129.9, 130.1, 130.8, 131.4, 133.6, 137.7, 138.1, 141.5, 141.9; $\mathrm{MS}\left(\mathrm{ESI}^{+}\right): \mathrm{m} / \mathrm{z}(\%)=368.7(100 \%)\left[\mathrm{M}^{+}, 524.1[\mathrm{M}-127(-\mathrm{I})]^{+}\right.$; Anal. Calcd for $\mathrm{C}_{27} \mathrm{H}_{31} \mathrm{I}_{2} \mathrm{~N}_{3}$ : C, 49.79; $\mathrm{H}, 4.80 ; \mathrm{N}, 6.45$. Found: $\mathrm{C}$, 49.66; $\mathrm{H}, 4.74 ; \mathrm{N}, 6.28$.

(E)-7-(4-(Diethyl(methyl)ammonio)styryl)-2-(4-methoxyphenyl)1-methylimidazo[1,2a]pyridin-1-ium iodide (2b). Light orange powder; $0.57 \mathrm{~g}$; yield 94\%; mp: $198-199{ }^{\circ} \mathrm{C} ;{ }^{1} \mathrm{H}$ NMR $\left(d_{6}\right.$-DMSO, $400 \mathrm{MHz}) \delta$ 1.02-1.06 (t, 6H), $3.52(\mathrm{~s}, 3 \mathrm{H}), 3.61-3.88(\mathrm{~s}, 3 \mathrm{H}$ for $-\mathrm{CH}_{3}$ attached imidazo- $\mathrm{N}^{+}$and $\mathrm{m}, 2 \mathrm{H}$, ethyl $\mathrm{CH}_{2}$ adjacent to the cationic nitrogen), $3.97(\mathrm{~s}, 3 \mathrm{H}), 4.07\left(\mathrm{~m}, 2 \mathrm{H}\right.$, ethyl $\mathrm{CH}_{2}$ adjacent to the cationic nitrogen), $7.21(\mathrm{~d}, 2 \mathrm{H}, J=8.8 \mathrm{~Hz}), 7.68(\mathrm{~d}, 2 \mathrm{H}), 7.70(\mathrm{~d}$,
$1 \mathrm{H}, J=16.1 \mathrm{~Hz}), 7.89-7.98(\mathrm{~m}, 6 \mathrm{H}), 8.43(\mathrm{br} \mathrm{s}, 1 \mathrm{H}), 8.50(\mathrm{~s}, 1 \mathrm{H})$, $8.92(\mathrm{~d}, 1 \mathrm{H}) ;{ }^{13} \mathrm{C} \mathrm{NMR}\left(d_{6}\right.$-DMSO, $\left.100 \mathrm{MHz}\right): \delta 8.67\left(2 \times \mathrm{CH}_{3}\right), 32.6$ $\left(\mathrm{CH}_{3}\right), 55.9\left(\mathrm{OCH}_{3}\right), 63.7\left(2 \times \mathrm{CH}_{2}\right), 108.4,112.7,115.2,115.5$, $117.6,123.3,127.9,129.0,129.2,131.6,133.5,137.7,138.1,141.4$, 141.6, 161.3; MS $\left(\mathrm{ESI}^{+}\right): \mathrm{m} / \mathrm{z}(\%)=398.6(100 \%)\left[\mathrm{M}^{+}, 554.0[\mathrm{M}-127\right.$ $(-\mathrm{I})]^{+}$; Anal. Calcd for $\mathrm{C}_{28} \mathrm{H}_{33} \mathrm{I}_{2} \mathrm{~N}_{3} \mathrm{O}: \mathrm{C}, 49.36 ; \mathrm{H}, 4.88 ; \mathrm{N}, 6.17$. Found: $\mathrm{C}, 49.40 ; \mathrm{H}, 4.75 ; \mathrm{N}, 6.24$.

\section{Materials}

The HSA (fatty acid-free) fraction $V$ was purchased from Sigma-Aldrich (St. Louis, MO, USA). Stock solutions of HSA and styryl dyes were prepared at concentrations of $1.0 \times 10^{-4} \mathrm{M}$ and $5.0 \times 10^{-4} \mathrm{M}$, respectively, with Tris- $\mathrm{HCl}$ buffer (0.05 M Tris base, $0.05 \mathrm{M} \mathrm{HCl}$ and $0.1 \mathrm{M} \mathrm{NaCl}$ in double-distilled water, $\mathrm{pH}$ 7.4). All experimental solutions were prepared from stock solutions by dilution with buffer and stored in a refrigerator at $4{ }^{\circ} \mathrm{C}$ until use.

\section{Apparatus and methods}

Fluorescence. Fluorescence measurements were taken on a Hitachi F-4500 spectrofluorometer (Tokyo, Japan) with a $150 \mathrm{~W}$ xenon lamp, using $1.0 \mathrm{~cm}$ quartz cells. Excitation and emission slits with band passes of $2.5 \mathrm{~nm}$ were used for all studies. The photomultiplier (PMT) voltage was kept at $700 \mathrm{~V}$ and the scan speed was $20 \mathrm{nmsec}^{-1}$. $\mathrm{pH}$ measurements were carried out using a NeoMet (pH -220 L) pH meter.

The interaction of $\mathbf{2} \mathbf{a}$ and $\mathbf{2} \mathbf{b}$ dyes with HSA was studied by the fluorescence quenching titration method using the intrinsic fluorescence of HSA at $\lambda_{\mathrm{ex}} / \lambda_{\mathrm{em}}=294 / 342 \mathrm{~nm}$ under two temperatures (298 and $310 \mathrm{~K}$ ). Various concentrations of HSA solution were added by microliter pipette to $3.0 \mathrm{~mL}$ of $1.0 \times 10^{-5} \mathrm{M} \mathrm{HSA}$ in Tris- $\mathrm{HCl}$ at $\mathrm{pH} 7.4$ in fluorescence cells. Fluorescence intensities and spectra of HSA in the presence of the dyes were recorded and titration data were analyzed according to the Stern-Volmer equation. Tryptophan fluorescence from HSA was corrected for the inner filter effect using the following equation (29),

$$
\mathrm{F}_{\text {cor }}=\mathrm{F}_{\text {obs }} 10^{(\text {Aex }+ \text { Aem }) / 2}
$$

where $F_{\text {cor }}$ and $F_{\text {obs }}$ are the corrected and observed fluorescence intensities, and $A_{e x}$ and $A_{e m}$ are the absorbances of the system at excitation and emission wavelengths.

Ultraviolet-visible absorption. Absorption spectra were recorded on a Thermo Scientific NanoDrop 2000 benchtop spectrophotometer (Thermo-Fisher Scientific, USA). Absorption spectra of HSA $\left(5.0 \times 10^{-5} \mathrm{M}\right)$ were taken before and after the addition of $\mathbf{2 a}$ and $\mathbf{2 b}$ dyes at $298 \mathrm{~K}$. All spectra were plotted using GraphPad Prism 5 software (La Jolla, CA) in the $200-450 \mathrm{~nm}$ range.

Circular dichroism. CD spectra were recorded on a Jasco J-815 spectropolarimeter (Jasco Inc., UK) using a quartz cell with a 
$0.1 \mathrm{~cm}$ path length in $\mathrm{pH} 7.4$ Tris- $\mathrm{HCl}$ buffer. $\mathrm{CD}$ spectra were obtained from 250 to $200 \mathrm{~nm}$ with a scan speed of $50 \mathrm{~nm} / \mathrm{min}$ at $298 \mathrm{~K}$ under constant nitrogen flush. CD spectra of HSA $\left(5.0 \times 10^{-6} \mathrm{M}\right)$ were taken in the presence and absence of $\mathbf{2 a}$ and $\mathbf{2} \mathbf{b}$ dyes. Each spectrum was the average of five successive scans and corrected by buffer signal. Data were analyzed using GraphPad Prism 5 software (La Jolla, CA). The $\alpha$-helix content of HSA was calculated from its molar ellipticity $(\theta)$ at $208 \mathrm{~nm}$ according to the following equation (30):

$$
\text { \%helix }=\left(-[\theta]_{208}-4000\right) /(33000-4000) \times 100
$$

\section{Results and discussion}

\section{Fluorescence quenching}

The quenching of intrinsic protein fluorescence by a molecule can be measured to characterize the binding properties of small molecules to proteins. There are three fluorophores in HSA; tryptophan, tyrosine and phenylalanine. The fluorescence of HSA is largely attributable to its tryptophan residue (Trp-214 in subdomain IIA) alone (31,32), since phenylalanine has a very low quantum yield and the fluorescence of tyrosine is almost totally quenched if it is near an amino group, a carboxyl group or a tryptophan (29). The intrinsic fluorescence of HSA from the Trp-214 residue and fluorescence emission at $410 \mathrm{~nm}$ of dicationic styrylimidazol pyridinium dye at $294 \mathrm{~nm}$ excitation wavelength are shown in Fig. 1(a). The fluorescence emission spectra of HSA with addition of various concentrations of $\mathbf{2} \mathbf{b}$ dye at $\lambda_{\mathrm{ex}}=294 \mathrm{~nm}$ at $298 \mathrm{~K}$ are shown in Fig. 1(b). The fluorescence intensity of HSA was found to decrease strongly with increasing concentrations of $\mathbf{2} \mathbf{a}$ and $\mathbf{2} \mathbf{b}$ dyes, suggesting that an interaction between dye and HSA results in a concentration-dependent quenching effect.
Fluorescence quenching is usually described by the Stern-Volmer equation (29),

$$
\mathrm{F}_{0} / \mathrm{F}=1+\mathrm{K}_{\mathrm{sv}}[\mathrm{Q}]=1+\mathrm{k}_{\mathrm{q}} \tau_{0}[\mathrm{Q}]
$$

where $F_{0}$ and $F$ are the steady-state fluorescence intensities of $\mathrm{HSA}$ in the absence and presence of $\mathbf{2} \mathbf{a}$ and $\mathbf{2} \mathbf{b}$ dyes. [Q] is the concentration of the quencher ( $\mathbf{2} \mathbf{a}$ and $\mathbf{2} \mathbf{b}) . K_{s v}$ is the Stern-Volmer quenching constant. $\mathrm{k}_{\mathrm{q}}$ is the quenching rate constant of the fluorophore (HSA) and $\tau_{0}$ is the average lifetime of the fluorophore without quencher $\left(\tau_{0}\right.$ of HSA $\sim 10^{-8} \mathrm{sec}$ ). Figure 2 shows linear Stern-Volmer plots obtained from fluorescence titrations at 298 and $310 \mathrm{~K} . \mathrm{K}_{\mathrm{sv}}$ values were calculated from the slopes of these graphs and $\mathrm{k}_{\mathrm{q}}$ values were obtained from the equation $\mathrm{K}_{\mathrm{sv}}=\mathrm{k}_{\mathrm{q}} \tau_{0}$. $\mathrm{K}_{\mathrm{sv}}$, and $\mathrm{k}_{\mathrm{q}}$ were found to decrease with increasing temperatures, suggesting that the quenching mechanism of fluorescence of HSA by $\mathbf{2} \mathbf{a}$ and $\mathbf{2} \mathbf{b}$ dyes was a static quenching (Table 1 ). The maximum scatter collision quenching constant, $\mathrm{k}_{\mathrm{q}}$ of various quenchers with the biopolymer is $2 \times 10^{10} \mathrm{~L} / \mathrm{mol} . \mathrm{sec}$ (33). Thus, the rate constants of the HSA quenching procedure initiated by $\mathbf{2} \mathbf{a}$ and $\mathbf{2} \mathbf{b}$ dyes are greater than the $\mathrm{k}_{\mathrm{q}}$ of the scatter procedure. This result confirms that a static quenching mechanism is operative for the formation of the HSA-dye complex.

The binding constant $\mathrm{K}_{\mathrm{b}}$ and binding number of dye molecules (n) with HSA can be determined according to the following equation,

$$
\log \left(\mathrm{F}_{0}-\mathrm{F}\right) / \mathrm{F}=\log \mathrm{K}_{\mathrm{b}}+\mathrm{n} \log [Q]
$$

where $\mathrm{K}_{\mathrm{b}}$ and $\mathrm{n}$ are the binding constant and number of binding sites for the HSA-dye system, respectively. Thus, the double-log plot of $\log \left(F_{0}-F\right) / F$ versus log $[Q]$ gives $K_{b}$ from the intercept and $\mathrm{n}$ from the slope of the curve at two temperatures. The values of $K_{b}$ and $n$ are shown in Table 2. The values of $K_{b}$ decreased with increasing temperature, which indicated that the complex would be partly decomposed by higher temperatures.
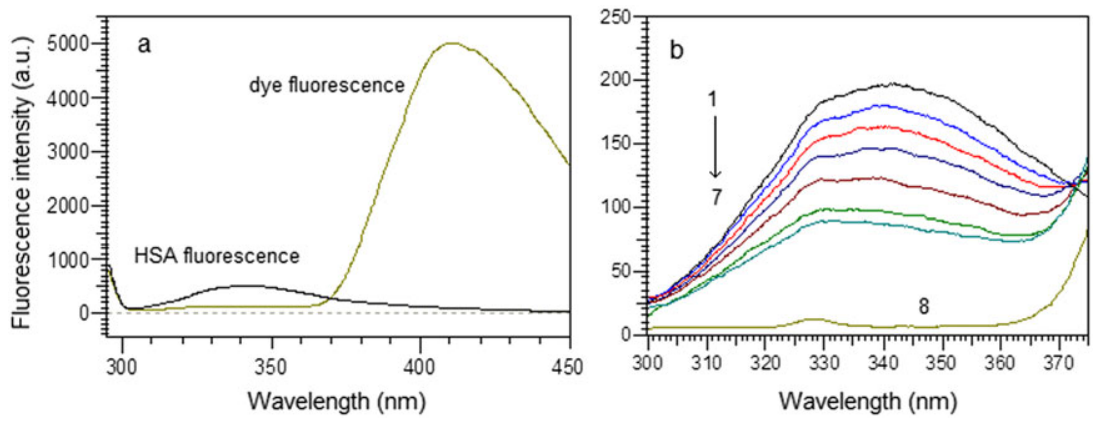

Figure 1. (a) Fluorescence emission spectra of $1.0 \times 10^{-5} \mathrm{M} \mathrm{HSA}$ and $1.0 \times 10^{-5} \mathrm{M} \mathbf{2 b}$ dye. Each spectrum was recorded at $\lambda_{\mathrm{ex}}=294 \mathrm{~nm}$ at $298 \mathrm{~K}$. (b) Fluorescence emission spectra of $1.0 \times 10^{-5}$ M HSA in the presence of $\mathbf{2 b}$ dye at $\lambda_{\text {ex }}=294 \mathrm{~nm}$ at $298 \mathrm{~K}$. The concentration range of dye from 1 to 7 is $0-1.0 \times 10^{-5} \mathrm{M}$. (Spectrum 8 is $1.0 \times 10^{-5} \mathrm{M}$ dye in the absence of HSA at these conditions.)
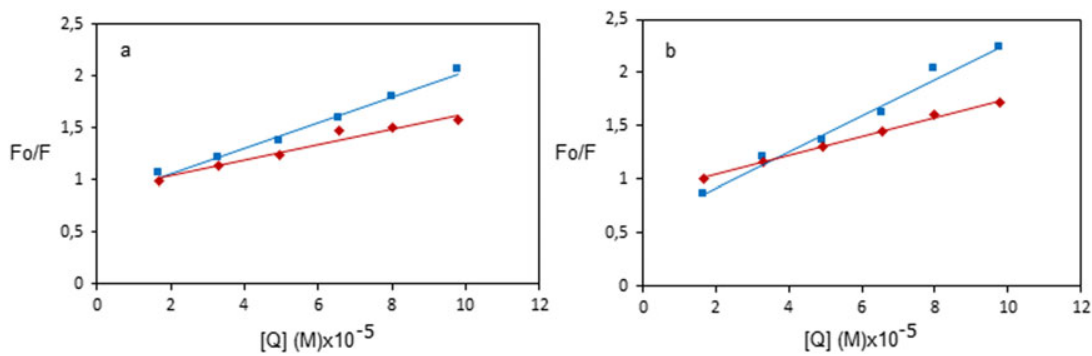

Figure 2. Stern-Volmer plots for the interaction of $1.0 \times 10^{-5} \mathrm{M} \mathrm{HSA}$ with $\mathbf{2 a}$ (a) and $\mathbf{2 b}$ (b) at 298 and $310 \mathrm{~K}$ (from high to low). 
Table 1. Stern-Volmer quenching $\left(\mathrm{K}_{\mathrm{sv}}\right)$ and quenching rate $\left(k_{\mathrm{q}}\right)$ constants for the HSA-dye systems at different temperatures

\begin{tabular}{lccccc} 
Dye & $\mathrm{T}(\mathrm{K})$ & $\begin{array}{c}\mathrm{K}_{\mathrm{sv}} \times 10^{4} \\
(\mathrm{~L} / \mathrm{mol})\end{array}$ & $\begin{array}{c}\mathrm{k}_{\mathrm{q}} \times 10^{12} \\
(\mathrm{~L} / \mathrm{mol} . \mathrm{sec})\end{array}$ & $\mathrm{R}^{\mathrm{a}}$ & $\mathrm{SD}^{\mathrm{b}}$ \\
\hline 2a & 298 & 12.3 & 12.3 & 0.986 & 0.083 \\
& 310 & 7.43 & 7.43 & 0.945 & 0.044 \\
$\mathbf{2 b}$ & 298 & 16.9 & 16.9 & 0.969 & 0.053 \\
& 310 & 8.67 & 8.67 & 0.999 & 0.036
\end{tabular}

${ }^{\mathrm{a}} \mathrm{R}$ is the correlation coefficient for the Stern-Volmer plot.

${ }^{\mathrm{b}} \mathrm{SD}$ is standard deviation for $\mathrm{K}_{\mathrm{sv}}$.

\section{Binding mode and thermodynamic parameters}

There are four non-covalent binding types between a small molecule and a biomolecule: hydrogen bonds, van der Waals forces, electrostatic forces and hydrophobic interaction forces. The signs and magnitudes of the thermodynamic parameters, including the enthalpy change $\left(\Delta \mathrm{H}^{\circ}\right)$ and entropy change $\left(\Delta \mathrm{S}^{\circ}\right)$ provide an account of the main forces involved in the binding reaction (34). The following, eqn 5 and eqn 6 , were used to calculate the thermodynamic parameters of HSA-dye system at 298 and $310 \mathrm{~K}$.

$$
\begin{aligned}
& \ln \mathrm{K}_{2} / \mathrm{K}_{1}=\Delta \mathrm{H}^{\circ} / \mathrm{R}\left[1 / \mathrm{T}_{1}-1 / \mathrm{T}_{2}\right] \\
& \Delta G^{\circ}=\Delta H^{\circ}-\mathrm{T} \Delta S^{\circ}=-\mathrm{R} \mathrm{T} \operatorname{lnK}
\end{aligned}
$$

where $\mathrm{K}_{1}$ and $\mathrm{K}_{2}$ are binding constants at 298 and $310 \mathrm{~K}$, and $\mathrm{R}$ is the gas constant. The calculated parameters are given in Table 2. The negative enthalpy change $\left(\Delta \mathrm{H}^{\circ}\right)$ associated with the dye-HSA binding interaction suggests that the process is exothermic. The negative free energy change $\left(\Delta G^{\circ}\right)$ values reveal that the binding process can occur spontaneously. Both $\Delta \mathrm{H}^{\circ}$ and $\Delta \mathrm{S}^{\circ}$ are negative for interaction between HSA and the dyes, indicating that binding was mainly enthalpy driven, that entropy was unfavourable, and that van der Waals forces and hydrogen bonds played a major role in the binding reaction.

\section{Ultraviolet-visible absorption studies}

UV absorption spectra of HSA in the presence or absence of $\mathbf{2} \mathbf{a}$ and $\mathbf{2 b}$ dyes at $298 \mathrm{~K}$ were recorded and presented in Fig. 3(a) and Fig. 3(b). The $280 \mathrm{~nm}$ absorption peak of HSA was observed to increase in intensity and experience a slight $(\sim 6 \mathrm{~nm})$ blueshift in a concentration-dependent manner in the presence of $\mathbf{2 a}$ or $\mathbf{2} \mathbf{b}$ dyes. Difference absorbance spectra of the dye-HSA complex were also obtained for $1 \times 10^{-5} \mathrm{M} \mathrm{HSA}$ and its complexes with dyes shown in Fig. 3(c) and Fig. 3(d). As seen from the figure, addition of dyes caused enhancement in the absorbance of serum albumin and the same blue shift was observed after substraction of the spectrum of free dye from its complex with protein. Although dyes had a small absorption peak around $260 \mathrm{~nm}$, they did not have a significant contribution to the change in maximum emission wavelength after complex formation. These results indicated that the absorption spectrum of HSA had changed due to the formation of dye-HSA complexes.

\section{Circular dichroism studies}

Circular dichroism (CD) is an optical analytical technique for the monitoring of secondary structural changes in proteins following their interaction with small molecules. The CD spectrum of HSA exhibited two negative bands at 208 and $222 \mathrm{~nm}$, which are characteristic of the typical $\alpha$-helix structure of the protein. The $208 \mathrm{~nm}$ band corresponds to a $\pi \rightarrow \pi^{*}$ transfer for the peptide bond of the $\alpha$-helix, whereas the $222 \mathrm{~nm}$ band is attributed to the $\pi \rightarrow \pi^{*}$ transfer for both the $\alpha$-helix and random coil (35). As shown in Fig. 4, the intensity of the two bands decreased significantly with the addition of $\mathbf{2} \mathbf{a}$ and $\mathbf{2} \mathbf{b}$ dyes, suggesting a change in the protein secondary structure and a decrease in the $\alpha$-helical content. The $\alpha$-helical content of HSA was calculated from eqn 2 and the results suggested a reduction of the $\alpha$-helix percent from $67 \%$ in free HSA to $62 \%$ and $59 \%$ upon $\mathbf{2} \mathbf{a}$ and $\mathbf{2} \mathbf{b}$ binding, respectively, indicating some degree of HSA defolding with the loss of helical stability.

\section{Energy transfer efficiency and FRET parameters}

Fluorescence resonance energy transfer (FRET) is a process in which an excited-stated donor can transfer energy to an acceptor through a long-range non-radiative dipole-dipole coupling $(36,37)$. Many reports have investigated the use of FRET for the determination of the interaction between a small molecule and a biomolecule based on fluorescence quenching (38). According to Förster's theory the energy transfer efficiency $E$ is calculated using the equation ((29)),

$$
\mathrm{E}=1-\mathrm{F} / \mathrm{F}_{0}
$$

$$
E=R_{0}{ }^{6} / R_{0}{ }^{6}+r^{6}
$$

where $\mathrm{F}$ and $\mathrm{F}_{0}$ are the fluorescence intensities of HSA (as donor)

\begin{tabular}{|c|c|c|c|c|c|c|c|c|}
\hline & $\mathrm{T}(\mathrm{K})$ & $\begin{array}{c}\mathrm{K}_{\mathrm{b}} \times 10^{6} \\
(\mathrm{~L} / \mathrm{mol})\end{array}$ & $n$ & $\mathrm{R}^{\mathrm{a}}$ & $S D^{b}$ & $\begin{array}{c}\Delta \mathrm{H}^{\circ} \\
(\mathrm{kJ} / \mathrm{mol})\end{array}$ & $\begin{array}{c}\Delta S^{\circ} \\
(\mathrm{J} / \mathrm{mol} . \mathrm{K})\end{array}$ & $\begin{array}{c}\Delta \mathrm{G}^{\circ} \\
(\mathrm{kJ} / \mathrm{mol})\end{array}$ \\
\hline \multirow[t]{2}{*}{$2 a$} & 298 & 60.9 & 1.55 & 0.999 & 0.092 & -229.5 & -621.2 & -44.41 \\
\hline & 310 & 1.69 & 1.28 & 0.944 & 0.075 & & & -36.96 \\
\hline \multirow[t]{2}{*}{$2 b$} & 298 & 26.1 & 1.47 & 0.979 & 0.066 & -115.8 & -246.4 & -42.31 \\
\hline & 310 & 4.28 & 1.35 & 0.996 & 0.056 & & & -39.36 \\
\hline
\end{tabular}
in presence or absence of $\mathbf{2} \mathbf{a}$ and $\mathbf{2} \mathbf{b}$ (as acceptor), $\mathbf{r}$ is the distance between the acceptor and the donor and $R_{0}$ is the critical distance

Table 2. Binding constants $\left(\mathrm{K}_{\mathrm{b}}\right)$, binding sites $(\mathrm{n})$ and thermodynamic parameters for HSA-dye systems at different temperatures 

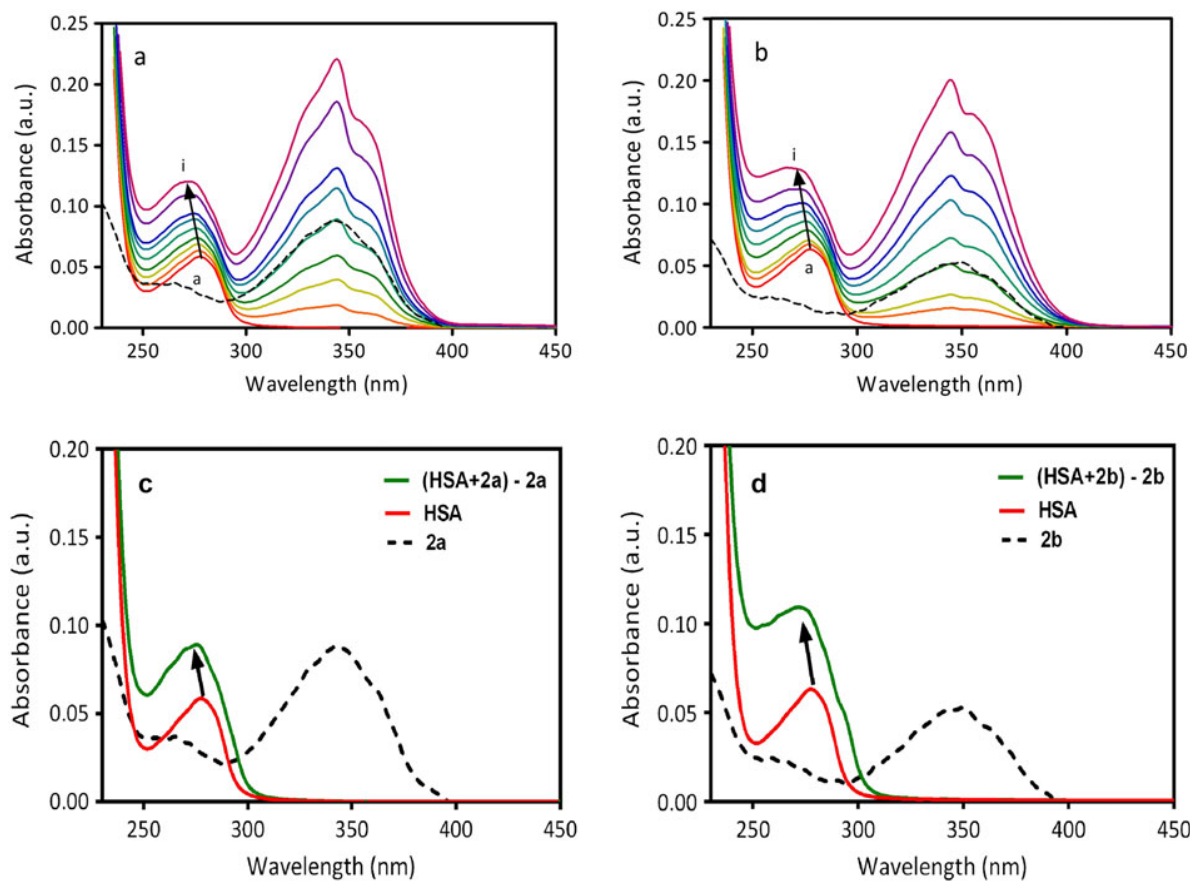

Figure 3. UV absorption spectra of $1.0 \times 10^{-5} \mathrm{M} \mathrm{HSA}$ in the presence or absence of $\mathbf{2 a}(\mathrm{a})$ and $\mathbf{2} \mathbf{b}(\mathrm{b})$ in $\mathrm{pH} 7.4$ at $298 \mathrm{~K}$. The concentration of dye from a to i is $0,0.1,0.2,0.4,0.6,0.8$, $1.0,2.0\left(\times 10^{-5}\right) \mathrm{M}$ (the dashed line shows the free dye spectrum). Difference UV absorption spectra of $0.4 . \times 10^{-5} \mathrm{M} \mathbf{2 a}(\mathrm{c})$ and $0.6 \times 10^{-5} \mathrm{M} \mathbf{2} \mathbf{b}(\mathrm{d})$.

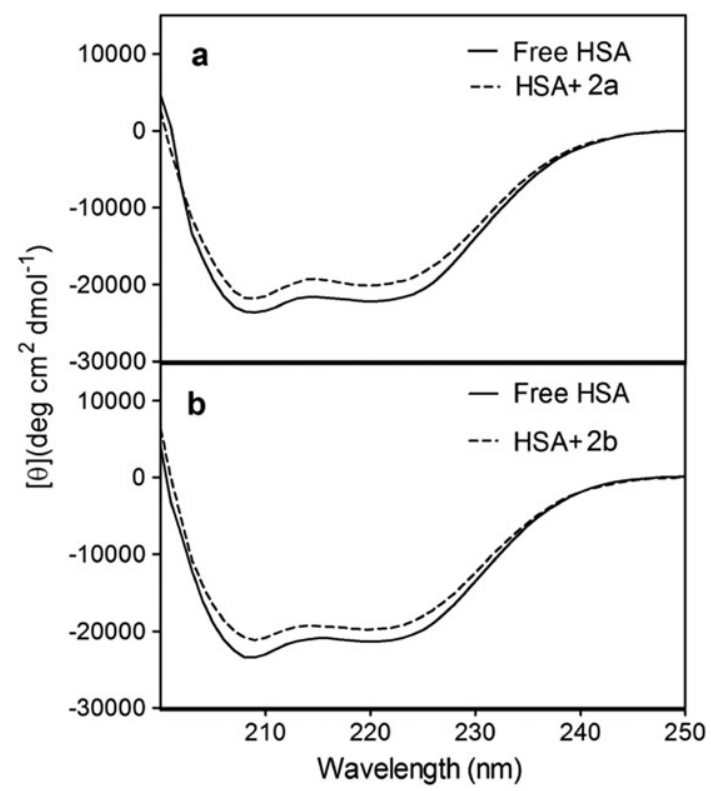

Figure 4. $C D$ spectra of HSA in the presence and absence of $\mathbf{2 a}(\mathbf{a})$ and $\mathbf{2} \mathbf{b}$ (b) in $\mathrm{pH} 7.4$ at $298 \mathrm{~K}$. $[\mathrm{HSA}]=5.0 \times 10^{-6} \mathrm{M}$ and $[$ dye $]=1.0 \times 10^{-4} \mathrm{M}$.

when the transfer efficiency is $50 \%$. The value of $\mathrm{R}_{0}$ was calculated using the equation,

$$
\mathrm{R}_{0}=0.211\left(\kappa^{2} n^{-4} \mathrm{Q}_{\mathrm{D}} J(\lambda)\right)^{1 / 6}
$$

where $\kappa^{2}$ is the spatial orientation factor of the donor-acceptor dipoles, $n$ is the refractive index of the medium, $Q_{D}$ is the fluorescence quantum yield of the donor in the absence of acceptor, $J$ $(\lambda)$ is the overlap integral of the fluorescence emission spectrum of the donor and the absorption spectrum of the acceptor, which is expressed by the equation,

$$
J(\lambda)=\Sigma \mathrm{F}_{\mathrm{D}}(\lambda) \varepsilon_{\mathrm{A}}(\lambda) \lambda^{4} \Delta \lambda / \Sigma \mathrm{F}_{\mathrm{D}}(\lambda) \Delta \lambda
$$

where $F_{D}(\lambda)$ is the corrected fluorescence intensity of the donor in the wavelength range $\lambda$ to $\lambda+\Delta \lambda$ with the total intensity (area under curve), and $\varepsilon_{A}(\lambda)$ is the extinction coefficient of the acceptor at $\lambda$. In this study, the overlap of the fluorescence emission spectrum of HSA (a), the absorption spectra of $\mathbf{2} \mathbf{a}(\mathrm{b})$ and $\mathbf{2} \mathbf{b}$ (c) was shown in Fig. 5 . So $J(\lambda)$ could be calculated by integrating the

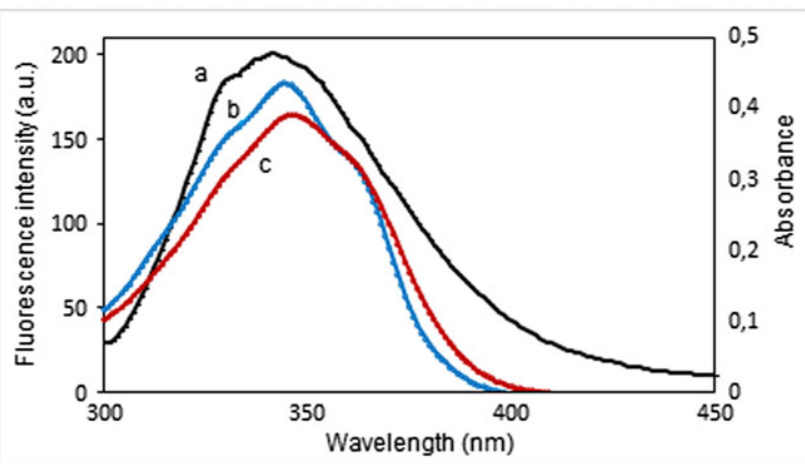

Figure 5. The overlap of fluorescence spectrum of (a) HSA, and the absorption spectra of (b) $\mathbf{2} \mathbf{a}$ and (c) $\mathbf{2} \mathbf{b}$. The concentrations of HSA, $\mathbf{2} \mathbf{a}$ and $\mathbf{2} \mathbf{b}$ are equal to $1.0 \times 10^{-5} \mathrm{M}$.

Table 3. Förster's resonance energy transfer data

\begin{tabular}{lcccc} 
Acceptor & $\begin{array}{c}\text { Spectral overlap, } \mathrm{J} \\
(\mathrm{L} / \mathrm{mol}) \mathrm{cm}^{3} \mathrm{~nm}^{4} \times 10^{14}\end{array}$ & $\begin{array}{c}\mathrm{R}_{0} \\
(\mathrm{~nm})\end{array}$ & $\begin{array}{c}\text { Transfer } \\
\text { efficiency } \mathrm{E} \\
(\%)\end{array}$ & $\begin{array}{c}\mathrm{r} \\
(\mathrm{nm})\end{array}$ \\
\hline 2a & 3.755 & 3.12 & 51.4 & 3.09 \\
2b & 3.623 & 3.32 & 55.2 & 3.21 \\
\hline
\end{tabular}


Table 4. Analytical results for determination of dyes in the presence of HSA

\begin{tabular}{lcccc} 
Dye & Sb $^{\mathrm{a}}$ & LOD (M) & LOQ (M) & $\mathrm{N}^{\mathrm{b}}$ \\
\hline 2a & 0.07656 & $1.87 \times 10^{-5}$ & $6.23 \times 10^{-5}$ & 5 \\
$\mathbf{2} \mathbf{b}$ & 0.1196 & $2.12 \times 10^{-5}$ & $7.07 \times 10^{-5}$ & 4 \\
& \\
${ }^{\mathrm{a}} \mathrm{Sb}$ is the standard deviation of the intercept. & \\
${ }^{\mathrm{b}} \mathrm{N}$ is the number of measurements. & \\
\end{tabular}

spectra in Fig. 5 for $\lambda=300-450 \mathrm{~nm}$ The distance parameters were calculated by $R_{0}$ from Eq. 9 and $r$ from eqn 8, respectively, using $\kappa^{2}=2 / 3, n=1.33$ and $Q_{D}=0.13$ (39). All related data were given in Table 3. The donor to acceptor distance $r$ is less than $8 \mathrm{~nm}$, which falls in the $0.5 R_{0}<r<1.5 R_{0}$ range, suggesting that non-radiative energy transfer occurred between HSA and dye. The larger values of $r$ compared with that of $R_{0}$ in the present study also revealed the presence of the static type of quenching mechanism.

\section{Analytical results}

The fluorescence quenching of HSA had a good relationship with the concentrations of $\mathbf{2} \mathbf{a}$ and $\mathbf{2} \mathbf{b}$ dyes. The calibration graphs were used for the determination of each dye in the presence of HSA under the experimental conditions described above. The linear Stern-Volmer equations at $298 \mathrm{~K}$ were used for calculations in Table 4, taking dynamic range of each dye as $1.66-10.0 \times 10^{-5} \mathrm{M}$. The detection limit (LOD) and quantification limit (LOQ) of dyes were calculated as $3 \mathrm{Sb} / \mathrm{m}$ and $10 \mathrm{Sb} / \mathrm{m}$, respectively (40). Sb is the standard deviation of the intercept, $m$ is the slope of the calibration graph.

To access the precision and accuracy of the measurements, the relative standard deviations (RSD) were obtained as $4.18 \%$ and $3.82 \%$ from replication of quenching experiments of $5.0 \times 10^{-6} \mathrm{M}$ concentration of $\mathbf{2 a}(\mathrm{N}=5)$ and $\mathbf{2 b}(\mathrm{N}=4)$, respectively.

\section{Conclusions}

We have characterized the binding of HSA with two novel dicationic styrylimidazo[1,2-a]pyridinium dyes, which have been synthesized through the integration of imidazopyridine units into styryl-type dicationic structures. Binding characteristics were explored by fluorescence, UV-vis absorption and CD spectroscopies. These dyes have strong abilities to quench the HSA fluorescence with a static mechanism by forming the HSA-dye complexes. The binding constant $\mathrm{K}$ and the number binding site $\mathrm{n}$ were calculated from the fluorescence data. The negative values of thermodynamic parameters $\left(\Delta \mathrm{H}^{\circ}\right.$ and $\left.\Delta \mathrm{S}^{\circ}\right)$ suggest that the binding of each dye could bind to HSA mainly through hydrogen bonding and van der Waals forces. The binding reaction between HSA and each dye is spontaneous and exothermic process. The values of binding distance, $r$, were less than $8 \mathrm{~nm}$ based on Förster theory which indicated that there was a non-radiative energy transfer between HSA and each dye. CD results have indicated that the $\alpha$-helical content of HSA decreases upon binding of dyes. The study has a significance to explain biological activities and protein binding properties of $\mathbf{2 a}$ and $2 \mathrm{~b}$. In this study, the investigation of the interaction of protein and dicationic styrylimidazo[1,2-a] pyridinium dyes may provide a good model that can be extended to the elucidation of the interaction between cationic styryl dyes and biomolecules.

\section{Acknowledgements}

Özdemir is supported by a TUBITAK BIDEB (2211) PhD fellowship.

\section{References}

1. Wang Q, Yan J, He J, Bai K, Li H. Characterization of the interaction between 3-oxotabersonine and two serum albumins by using spectroscopic techniques. J Lumin 2013;138:1-7.

2. Cheng Z. Interaction of ergosterol with bovine serum albumin and human serum albumin by spectroscopic analysis. Mol Biol Rep 2012;39:9493-508.

3. Bi S, Song D, Tian Y, Zhou X, Liu Z, Zhang H. Molecular spectroscopic study on the interaction of tetracyclines with serum albumins. Spectrochim Acta Part A 2005;61:629-36.

4. Yang H, Liu Q, Zhao L, Yuan Y, Fan D, Deng J, et al. Fluorescence spectroscopic studies on the interaction of oleanolic acid and its triterpenoid saponins derivatives with two serum albumins. J Solut Chem 2014;43:774-86.

5. Hongwei Z, Min G, Zhaoxia Z, Wenfeng W, Guozhong W. Spectroscopic studies on the interaction between riboflavin and albumins. Spectrochim Acta Part A 2005;65:811-7.

6. Shobini J, Mishra AK, Sandhya K, Chandra N. Interaction of coumarin derivatives with human serum albumin: Investigation by fluorescence spectroscopic technique and modeling studies. Spectrochim Acta Part A 2001;57:1133-47.

7. Gökoğlu E, Kıpçak F, Seferoğlu Z. Studies on the interactions of 3,6-diaminoacridine derivatives with human serum albumin by fluorescence spectroscopy. Luminescence 2014;29:872-7.

8. Liu J, Yue Y, Wang J, Yan X, Liu R, Sun Y, Li X. Study of interaction between human serum albumin and three phenanthridine derivatives: Fluorescence spectroscopy and computational approach. Spectrochim Acta Part A 2015;145:473-81.

9. Yue Y, Dong Q, Zhang Y, Li X, Yan X, Sun Y, et al. Synthesis of imidazole derivatives and the spectral characterization of the binding properties towards human serum albumin. Spectrochim Acta Part A 2016;153:688-703.

10. Yue Y, Sun Y, Dong Q, Liu R, Yan X, Zhang Y, et al. Interaction of human serum albumin with novel imidazole derivatives studied by spectroscopy and molecular docking. Luminescence 2016;31:671-81.

11. Li D, Hong D, Guo H, Chen J, Ji B. Probing the influences of urea on the interaction of sinomenine with human serum albumin by steady-state fluorescence. J Photochem Photobiol B 2012;117:126-31.

12. Yue Y, Liu J, Liu R, Sun Y, Li X, Fan J. The binding affinity of phthalate plasticizers-protein revealed by spectroscopic techniques and molecular modeling. Food Chem Toxicol 2014;71:244-53.

13. Yue Y, Liu J, Liu R, Dong Q, Fan J. Binding of helicid to human serum albumin: A hybrid spectroscopic approach and conformational study. Spectrochim Acta Part A 2014;124:46-51.

14. Liu J, Yue Y, Liu M, Zhang N, Zhuo K. Synthesis and interaction studies of benzimidazole derivative with human serum albumin. Spectrochim Acta Part A 2011;82:299-305.

15. Kovalska VB, Losytskyy MY, Kryvorotenko DV, Balanda AO, Tokar VP, Yarmoluk SM. Synthesis of novel fluorescent styryl dyes based on the imidazo[1,2-a]pyridinium chromophore and their spectral-fluorescent properties in the presence of nucleic acids and proteins. Dyes Pigments 2006;68:39-45.

16. Aranda Al, Achelle S, Hammerer F, Mahuteau-Betzer F, Teulade-Fichou MP. Vinyl-diazine triphenylamines and their $N$-methylated derivatives: synthesis, photophysical properties and application for staining DNA. Dyes Pigments 2012;95:400-7.

17. Xie X, Choi B, Largy E, Guillot R, Granzhan A, Teulade-Fichou MP. Asymmetric distyrylpyridinium dyes as red-emitting fluorescent probes for quadruplex DNA. Chem Eur J 2013;19:1214-26.

18. Zhao F, Gvishi R, Narang U, Ruland G, Prasad PN. Structures, spectra, and lasing properties of new (aminostyryl)pyridinium laser dyes. J Phys Chem 1996;100:4526-32.

19. Zheng Q, He GS, Lin TC, Prasad PN. Synthesis and properties of substituted ( $p$-aminostyryl)-1-(3-sulfooxypropyl)pyridinium inner salts as a new class of two-photon pumped lasing dyes. J Mater Chem 2003;13:2499-504. 
20. Deligeorgiev T, Vasilev A, Kaloyanova S, Vaquero JJ. Styryl dyes-synthesis and applications during the last 15 years. Color Technol 2010;126:55-80.

21. Fan L, Fu YJ, Liu QL, Lu DT, Dong C, Shuang SM. Novel far-visible and near-infrared $\mathrm{pH}$ probes based on styrylcyanine for imaging intracellular pH in live cells. Chem Commun 2012;48:11202-4.

22. Kamal A, Surendranadha RJ, Ramaiah MJ, Dastagiri D, Bharathi EV, Sagar MVP, et al. Design, synthesis and biological evaluation of imidazopyridine/pyrimidine-chalcone derivatives as potential anticancer agents. Med Chem Commun 2010;1:355-60.

23. Lacerda RB, De Lima CK, Da Silva LL. Discovery of novel analgesic and anti-inflammatory 3-arylamine-imidazo[1,2-a]pyridine symbiotic prototypes. Bioorg Med Chem 2009;17:74-84.

24. Almirante L, Polo L, Mugnaini A, Provinciali E, Rugarli P, Biancotti A, et al. Derivatives of imidazole. I. Synthesis and reactions of imidazo $[1,2-\alpha]$ pyridines with analgesic, antiinflammatory, antipyretic, and anticonvulsant activity. J Med Chem 1965;8:305-12.

25. Seferoğlu Z, Ihmels H, Şahin E. Synthesis and photophysical properties of fluorescent arylstyrylimidazo[1,2-a]pyridine-based donor-acceptor chromophores. Dyes Pigments 2015;113:465-73.

26. Aydıner B, Yalçın E, Ihmels H, Arslan L, Açık L, Seferoğlu Z. Arylstyrylimidazo[1,2-a]pyridine-based donor-acceptor acidochromic fluorophores: Synthesis, photophysical, thermal and biological properties. J Photochem Photobiol A: Chem 2015;310:113-21.

27. Fu X-B, Lin Z-H, Liu H-F, Le X-Y. A new ternary copper(II) complex derived from 2-(20-pyridyl) benzimidazole and glycylglycine: Synthesis, characterization, DNA binding and cleavage, antioxidation and HSA interaction. Spectrochim Acta Part A 2014;122:22-33.

28. Yellol J, Perez SA, Buceta A, Yellol G, Donaire A, Szumlas $P$, et al. $\mathrm{N}$-cyclometalated benzimidazole ruthenium(II) and iridium(III) complexes as antitumor and antiangiogenic agents: a structure-activity relationship study. J Med Chem 2015;58:7310-27.

29. Lakowicz JR. Principles of fluorescence spectroscopy. 3rd ed. New York: Plenum, 2006
30. Varlan A, lonescu S, Hillebrand M. Study of the interaction between ofloxacin and human serum albumin by spectroscopic methods. Luminescence 2011;26:710-5.

31. Sulkowska A. Interaction of drugs with bovine and human serum albumin. J Mol Struct 2002;614:227-32.

32. Kalanur SS, Seetharamappa J, Kalalbandi VKA. Characterization of interaction and the effect of carbamazepine on the structure of human serum albumin. J Pharm Biomed Anal 2010;53:660-6.

33. Matei I, Hillebrand M. Interaction of kaempferol with human serum albumin: A fluorescence and circular dichroism study. J Pharm Biomed Anal 2010;51:768-73.

34. Ross PD, Subramanian S. Thermodynamics of protein association reactions: forces contributing to stability. Biochemistry 1981;20:3096-102.

35. Whitmore L, Wallace BA. Protein secondary structure analyses from circular dichroism spectroscopy: methods and reference databases. Biopolymers 2008;89:392-400.

36. Sahoo H. Förster resonance energy transfer-A spectroscopic nanoruler: Principle and applications. J Photochem Photobiol C Photochem Rev 2011;12:20-30.

37. De S, Girigoswami A. Fluorescence resonance energy transfer-a spectroscopic probe for organized surfactant media. J Colloid Interface Sci 2004;271:485-95.

38. Britton J, Antunes E, Nyokong T. Fluorescence quenching and energy transfer in conjugates of quantum dots with zinc and indium tetraamino phthalocyanines. J Photochem Photobiol A Chem 2010;210:1-7.

39. Bi S, Yan L, Sun Y, Zhang H. Investigation of ketoprofen binding to human serum albumin by spectral methods. Spectrochim Acta Part A 2011;78:410-4.

40. Zhu C, Zheng H, Li D, Li S, Xu J. Fluorescence quenching method for the determination of sodium dodecyl sulphate with near-infrared hydrophobic dye in the presence of Triton X-100. Spectrochim Acta Part A 2014;60:3173-9. 